\title{
Estado, mercado e índices de sustentabilidade*
}

Marina de Souza Sartore ${ }^{1}$

Resumo: Este artigo consiste em um estudo teórico que tem por objetivo colaborar para a reflexão sobre a necessidade de uma nova abordagem sociológica no Brasil, que não apenas utilize os índices como instrumentos de análise para a pesquisa, mas que reflita sobre como a sociedade foi reorientada e reconfigurada a partir deles. Para delinear teoricamente esta nova linha de pesquisa, utilizo os trabalhos de Foucault, Hacking, Porter, Desrosières e Goede. Por fim, aponto o surgimento dos índices de sustentabilidade na esfera pública e, particularmente, na esfera financeira, vistos como possíveis elementos centrais para a compreensão das atuais configurações de poder na sociedade brasileira, a qual vem incorporando, cada vez mais, essas ferramentas de mensuração de diferentes aspectos da realidade social.

Palavras-chave: Índices, Estado, Mercado Financeiro, Sustentabilidade, Sociologia da Ciência.

$\mathrm{E}$ m carta escrita ao Rei Manoel I, Pero Vaz de Caminha relata as suas impressões sobre a terra que acabara de descobrir: "Parece-me gente de tal inocência que, se o homem os entendesse e eles a nós, seriam logo cristãos, porque eles, segundo parece, não têm nem entendem em nenhuma crença" (CAMINHA, 1500). Essa fala nos remete ao século XVI quando houve o encontro entre dois mundos completamente diferentes: o indígena e o europeu. Naquele período, os europeus explicavam os nascimentos, as mortes e os casamentos a partir da crença no determinismo divino. Hacking $(1990$, p. 21) relata a tese de John Arbuthnot, desenvolvida em 1710, a qual procura provar a existência da Providência Divina a partir do fato de que, regularmente, nasciam mais meninos do que meninas. Para Arbuthnot, isso não era o resultado do acaso ou de pura sorte, mas sim, da vontade divina em "repor" os homens que morriam no mar e nas guerras.

O encontro de uma visão de mundo "cristã europeia" e "indígena não cristã" é emblemático, pois a necessidade dos europeus em controlar as suas colônias contribuiu para que eles questionassem a crença no determinismo divino, substituindo-a pela crença no determinismo da espécie humana, característica marcante do período renascentista.

A desvinculação de uma visão de mundo pautada no determinismo divino para a visão na centralidade do homem moldou a sociedade contemporânea, a qual incorporou essa crença como naturalmente estabelecida, obscurecendo, portanto,
Recebido:

19.11.10

Aprovado:

23.10.12

1. Universidade Federal de Goiás. Programa de PósGraduação em Ciência Política - UFG E-mail: marina. ufg@gmail.com

* Agradeço os preciosos comentários do Prof. Roberto Grün, orientador da tese da qual este artigo é fruto. 
os mecanismos de sua construção social. Ao utilizar a expressão naturalmente estabelecida, refiro-me à ideia explicitada por Pierre Bourdieu, na qual a atitude dita natural corresponde à concordância entre as estruturas objetivas e as estruturas subjetivas, capazes de transformar um arbitrário cultural em algo natural, "deixando de lembrar as condições sociais de sua possibilidade" (BOURDIEU, 1999, p. 17).

Neste artigo, recupero, ao menos, algumas condições sociais que permitiram o estabelecimento dessa crença na centralidade humana a partir da reflexão sobre como passamos de uma sociedade que buscava, na vontade divina, a explicação para os nascimentos, os casamentos e as mortes, para uma sociedade que atribui, aos dados estatísticos produzidos pelo homem, o controle e a previsão desses acontecimentos.

Segundo Hacking (1990), o surgimento da capacidade de previsão pelo homem está associado à avalanche dos números impressos, que tem por corolário o nascimento da sociedade estatística. Através do uso das estatísticas, não seria somente possível tentar prever o número de mortes, nascimentos e casamentos, mas, também, os acontecimentos em outras esferas da vida social, como, por exemplo, a quantidade da produção agrícola em um determinado período de tempo (DIDIER, 2007).

Paulatinamente, essas informações estatísticas passaram a ser representadas por gráficos e índices numéricos que vieram a ocupar um papel central na sociedade contemporânea. A todo o momento, nos deparamos com eles, seja na esfera global: "Brasil Melhora Índices, mas segue em 70으 no ranking do desenvolvimento" (LYRA, 2008); nacional: "PIB cresce 1,6\% em relação ao primeiro trimestre de 2008" (IBGE, 2008); ou local: "São Paulo envelhece e jovens deixam de ser maioria no Estado" (FRANÇA, 2007).

O desenvolvimento do contexto do surgimento de índices globais, nacionais e locais consiste em uma tarefa tanto desafiadora, quanto exaustiva, pois, apesar de terem um ancestral filosófico em comum, eles se ramificaram e se diversificaram. No entanto, sem menosprezar esse passado em comum dos diferentes índices que hoje nos circundam, o desenvolvimento deste artigo é estruturado da seguinte maneira: em uma primeira parte aponto as transformações pelas quais passou a sociedade que nos levaram à sociedade da estatística. Estas transformações são apresentadas em cinco tópicos distintos: (1.1) A regularidade intrínseca, (1.2) A virada cognitiva, (1.3) A lei dos grandes números, (1.4) O homem médio, (1.5) Do patológico ao normal. Em uma segunda parte, apresento a evolução dos índices no mercado de capitais para, posteriormente, mencionar o surgimento dos Índices de Sustentabilidade (tanto na esfera pública e principalmente no mercado de capitais), para construir a hipótese de que 
eles podem ser considerados elementos potenciais para se compreender as configurações de poder na sociedade brasileira.

Desse modo, o objetivo deste artigo é o de apresentar um estudo teórico, reconstituindo algumas ideias desenvolvidas, principalmente, entre os séculos XVIII e XIX, quando a sociedade, entre Deus e Índices, optou pelos últimos e os transformou em seu novo oráculo.

\section{A previsibilidade e as formas de exercício de poder}

O desenvolvimento da capacidade de prever e controlar os acontecimentos na sociedade ocidental caminha de mãos dadas com o desenvolvimento de diferentes modos de governar, ou seja, com a transformação das bases de exercício do poder.

Foucault (1994) nos aponta três formas de governo que correspondem, respectivamente, a três momentos-chave e distintos desse processo: o primeiro é o Conselho do Príncipe, seguido pela Arte de Governar e, por fim, a Governabilidade.

O primeiro momento, o conselho do príncipe, é situado na Idade Média, quando a base para o poderio do príncipe era ideológica e material. Na primeira, o poder estava nos conselhos dos príncipes, os quais faziam "reinar a lei de Deus na cidade dos homens" (FOUCAULT, 1994, p. 635). Na segunda, o poder estava nas conquistas territoriais, independentemente de seus habitantes ou da produção de riqueza proveniente dele.

A passagem para a arte de governar descrita por Foucault (1994) consiste na contestação da ideia de que a base de governo do príncipe estava somente na propriedade de seus territórios. Pelo ponto de vista desses contestadores, o poderio do príncipe deveria ser baseado na economia, ou seja, na "maneira de gerir como se deve os indivíduos, os bens, as riquezas como se o fizesse no seio de uma família" (ibidem, p. 641). O despertar para a necessidade de governar um território como se governasse uma família com bens, riquezas e indivíduos possibilitou o surgimento dos políticos aritméticos, os quais contavam os nascimentos, casamentos e óbitos, transformando-os em informações numéricas as quais caracterizavam a população para o monarca. Essas informações não eram divulgadas, pois consistiam na medida da "riqueza e do poder do Estado [que] dependiam fortemente do número e das características de seus sujeitos" (PORTER, 1986, p. 19).

Em suma, se, em um primeiro momento, o poder do príncipe era baseado 
na propriedade do seu território, em um segundo momento, o poder do monarca estava baseado nas características de sua população, fornecidas pelos políticos aritméticos.

Segundo Hacking (1990), essa preocupação em contar a população levou ao aparecimento dos censos populacionais para que as metrópoles pudessem contar e classificar as suas colônias e, consequentemente, garantir seu poderio sobre elas. Porém, como nos mostra o autor, a contagem e a classificação da população eram arbitrárias: enquanto, nos Estados Unidos, no século XVI, os negros do sul eram contados e classificados como equivalentes a três quintos de pessoa, na Prússia do século XIX, as pessoas eram civis ou militares antes mesmo de serem consideradas mulheres ou homens.

Tal arbitrariedade criou a necessidade constante de novas categorias para qualificar os indivíduos, transformando os censos em verdadeiras "tecnologias que manipulam ou transformam o que supostamente eles deveriam representar" (HANNAH apud GOEDE, 2005 [1971], p. 88). Esse poder de transformação da realidade, atribuído ao ato de medir e classificar, é discutido por Hacking (1986), quando expõe o debate entre os nominalistas, aqueles que creem que a existência de uma nomenclatura cria uma realidade, versus os realistas, aqueles que creem que existe uma entidade real antes mesmo de ser nomeada. Hacking os critica adotando a perspectiva do nominalismo dinâmico, que expressa uma criação dinâmica da realidade, ou seja, um "tipo" de pessoa passa a existir, ao mesmo tempo em que o "tipo" é inventado. Pensando por essa perspectiva, os censos, ao mesmo tempo em que nomeiam ou codificam, criam os tipos, ou seja, as categorias através das quais os indivíduos passam a se classificar e a se definir.

Porter (1986) e Hacking (1990) apontam duas obras emblemáticas que ilustram a passagem de uma sociedade enviesada pela política aritmética, para uma sociedade governada pela estatística. Do lado da política aritmética, aparece a obra de Peter Süssmilch, Divine Order, cuja primeira publicação data de 1740. De outro lado, aparece a obra de Thomas Robert Malthus, An essay on the principle of population publicada após a Revolução Francesa, em 1798.

A obra de Süssmilch consiste em um intenso estudo sobre as taxas de nascimento, morte, assim como as taxas de homens ou mulheres, procurando explicar as suas regularidades como decorrentes da vontade divina. No entanto, Süssmilch militava pela "expansão do aparato do governo para coletar os números da população e, ainda mais, para agir sobre ela" (PORTER, 1986, p. 23). Nesse sentido, é possível aproximar Süssmilch à ideia dos políticos aritméticos, a partir de seu apoio sobre a relação positiva entre a contagem da crescente população, associada ao crescimento do poder do Estado (PORTER, 1986). 
Como uma ruptura, a obra de Malthus coloca em xeque o pressuposto de aumento do poder do Estado pelo aumento da população adotado pelos políticos aritméticos. De modo contrário, Malthus afirmou que a população crescia de maneira geométrica enquanto a produção de alimentos aumentava aritmeticamente: esta seria a causa da miséria e da fome pela qual a sociedade daquele momento passava. Desse modo, conclui que a culpa para a fome e a miséria não estava em Deus, mas sim na própria população que crescia e que, portanto, adquiria uma "uma dimensão de existência mais fundamental do que a do Estado ou a do governo" (PORTER, 1986, p. 27).

O trabalho de Malthus contribuiu triplamente para a transformação da forma de exercício do poder pelo Estado: primeiramente, desenvolveu a percepção de que a sociedade tem regularidades que lhe são inerentes, ou seja, "as leis dos acontecimentos se encontravam nas estruturas internas da sociedade humana" (PORTER, 1986, p. 27). Em segundo lugar, focou as atenções para o "problema da população", que consistia na preocupação com "a simultaneidade da explosão populacional e da baixa taxa de nascimento dentre os seus pares" (HACKING, 1990, p. 22), suscitando uma preocupação por parte da elite dominante em desenvolver maneiras melhores para controlar o crescimento da população. Em terceiro lugar, tanto a crença em uma regularidade intrínseca à sociedade, quanto o problema da crescente população possibilitaram o surgimento do terceiro momento explicitado por Foucault (1994) o qual ele chama de Governabilidade, melhor explicitado no item 1.2.

\section{a) Uma regularidade intrínseca}

A crença na presença de regularidades que seriam causadas pela própria população foi fundamental para derrubar a crença de que as regularidades nela encontradas pertenciam ao arbitrário divino. Essa nova percepção sobre a sociedade trouxe o que Porter (1986) denomina de a "era do entusiasmo", na qual a ciência é representada por estatísticos. Nas palavras de Porter, o interesse dos estatísticos contribuiu

(...) com uma medida de expertise para questões sociais, para substituir as pré-concepções contraditórias de partes interessadas pela certeza de uma observação empírica cuidadosa. Eles acreditavam que as confusões políticas podiam ser substituídas pelo ordenado reino dos fatos. (PORTER, 1986, p. 27)

A aparição dos estatísticos molda uma nova etapa, que ultrapassa a exclusividade da produção de dados estatísticos pelos burocratas do Estado, possibilitando sua produção por indivíduos na esfera privada. Como nos aponta Hacking 
2. $O$ artigo de Desrosières citado data de uma segunda versão (2001), de um artigo apresentado em uma conferência em Quebec, em 1999 (ver referências).
(1990), devido à euforia para a publicação de dados estatísticos, foi possível a ocorrência da "avalanche dos números impressos" a qual consiste na explosão, a partir de 1820, da publicação de periódicos recheados de dados estatísticos. Segundo o autor, se em 1800 não havia periódicos com publicações sobre o assunto, em 1860, havia 410 (HACKING, 1990, p. 33).

Esse deslocamento de autoria sobre a produção dos dados estatísticos propiciou o desenvolvimento de escritórios de estatística, que tinham duas características novas: a sua independência para a produção dos dados e o seu entusiasmo para publicá-los para quem quisesse lê-los, de maneira que esses dados não seriam mais segredos de Estado.

Essa grande disponibilidade de dados sobre a população propiciou o problema da população, ou seja, incitou o questionamento daqueles que possuem o exercício do poder sobre como controlar uma população que não pertence à elite e que só cresce? Para solucionar esse problema, surgiu a utilização científica dos dados estatísticos pelo Estado. Mas, para que isso fosse possível, foi necessário que a sociedade fosse vista "não apenas somente como um espaço político unificado, mas também como um espaço cognitivo comum, observado e descrito através de esquemas interpretativos consistentes" (DESROSIÈRES, 2001 [1999] p. 04). Mas, quais seriam esses esquemas interpretativos consistentes? São as próprias estatísticas do Estado que, como nos aponta Foucault (1994, p. 651), "mostram igualmente que a população tem os efeitos próprios à sua agregação e que estes fenômenos são irredutíveis àqueles da família: serão eles as grandes epidemias, as expansões endêmicas, a espiral do trabalho e da riqueza". A produção das estatísticas pelo Estado abre caminhos para a virada cognitiva do século XIX sobre a qual nos debruçaremos no item a seguir.

\section{b) A virada cognitiva}

O Estado Administrativo, cujo poder era pautado pela contagem e classificação dos indivíduos, principalmente pela aplicação dos censos populacionais, é transformado no Estado Estatístico.

Esse é o terceiro momento citado por Foucault (1994), o da Governabilidade, o qual consiste na maneira de governar cada indivíduo subordinando-o às regras da própria população a qual pertence e utilizando as estatísticas como seu instrumento (ibidem, 1994). Como afirma Santos (2005, p. 32), é a partir das estatísticas que "decisões serão tomadas e categorias feitas e refeitas. Indivíduos, antes confusos na dispersão do mundo, agora encontram nas individualizações produzidas seu lugar em uma dada hierarquia social". 
O Estado Estatístico “age por meio de médias estatísticas” (DESROSIÈRES, 1996, p. 12), ou seja, age sobre uma população na qual os indivíduos são colocados em situação de equidade e equivalência, para que possam ser elaboradas médias nacionais. A transformação do modo de pensar a população enquanto soma dos indivíduos, para a população enquanto uma média dos mesmos consiste na virada cognitiva do século XIX. Mas, como ocorreu essa supracitada virada cognitiva?

A crença na regularidade inerente à sociedade permitiu o desenvolvimento de pesquisas e experiências, com o intuito de entender a sua imanente lógica social. Hacking (1990) demonstra, de maneira exemplar, em seu livro The taming of chance, as sucessivas experiências realizadas na sociedade com o objetivo de controlar o acaso. Não nos debruçaremos sobre essas numerosas tentativas, pois ultrapassaria os limites desta argumentação. No entanto, na próxima seção, destacarei três dos momentos descritos por Hacking (1990), que considero relevantes para reconstituirmos e refletirmos sobre essa virada cognitiva.

\section{c) Primeiro momento: "A lei dos grandes números"}

Para chegarmos a uma sociedade que se reconhece e é reconhecida por médias estatísticas, apresento três momentos sequenciais vistos como "divisores de águas" pelos estudiosos da sociologia das ciências, particularmente por Hacking $^{3}$ (1990).

Em um primeiro momento, houve a descoberta de que era possível encontrar uma regularidade para todos os tipos de acontecimentos, como, por exemplo, o número de nascimento de homens a partir de certo número de partos realizados. A descoberta dessas regularidades culminou na "Lei dos Grandes Números". Segundo Hacking (1990), a "lei dos grandes números" surgiu a partir das observações de Poisson, em 1835, sobre a possível previsão da frequência de um acontecimento em grandes populações.

Por isso, se inspira no teorema de Jacques Bernoulli, publicado postumamente em 1713, no qual temos que imaginar uma urna com bolas pretas e brancas. Em um primeiro momento, retiramos uma bola e anotamos a sua cor; em seguida, devolvemos a bola à urna, mexemos e retiramos uma bola novamente. Segundo Bernoulli, considerando uma sequência limitada de retiradas, poderíamos verificar, com uma pequena margem de erro, qual a frequência em que a bola preta é retirada.

Poisson acrescenta a esse teorema a ideia de população. Para ele, a suposição é a de que, ao invés de uma única urna, existem várias urnas com uma distribuição
3. A inclusão dessas teorias para descrever o processo de transformação cognitiva para o Estado Estatístico advém, fundamentalmente, da análise dos trabalhos de Hacking (1990), Porter (1986) e Desrosières (1996). 
diferente de bolas pretas e brancas dentro de cada uma delas. Em uma sequência de tentativas, é escolhida aleatoriamente uma urna e retirada uma bola também aleatoriamente. A bola é devolvida e a operação é repetida. Ao verificar a frequência da retirada de bolas pretas, ele observou que essa frequência também era constante.

Poisson chamou o fato de a frequência de retiradas de bolas pretas de diferentes urnas ser constante de a "Lei dos Grandes Números". Adolph Quetelet transferiu esse princípio para as ciências morais, ou seja, "o casamento, o suicídio, ou a morte de um indivíduo são similares às retiradas aleatórias de urnas constantes nas quais a composição é revelada pelas estatísticas do estado-civil" (DESROSIÈRES, 1995).

Assim, transferindo esse princípio para a sociedade, seria possível prever quantos navios afundariam de um total de navios que partiram ou ainda, a probabilidade de nascimento de homens em um número específico de nascimentos. Assim, entidades tão diferentes quanto o afundar de um navio ou o nascimento de um ser humano equivalem a bolas de urnas, suscetiveis a constantes, criando as condições para o estabelecimento de leis para prever as suas ocorrências.

Como nos aponta Hacking (1990, p. 104), foi “a lei dos grandes números - não o teorema de Poisson, mas [sim] a proposição sobre a estabilidade do fenômeno da população - [que] se tornou, para as duas próximas gerações, uma verdade sintética a priori". Assim, um primeiro momento crucial para a virada cognitiva foi a criação da crença de que existia uma constância nos acontecimentos relativos à sociedade e a identificação dessa constância possibilitou a previsão desses acontecimentos através do uso da probabilidade.

\section{d) Segundo momento: o homem médio}

Em um segundo momento, a regularidade passou a ser considerada quanto às características de uma população. Seguindo o exemplo de Quetelet, podemos imaginar que uma população tenha muitos homens de 1,80 cm de altura. Quando a sua altura média for calculada, verificar-se-á que, em média, a população tem 1,80 cm. A constância refletida pela média das características de uma população abre caminhos para a constituição da ideia de "homem médio".

Em 1835, Quetelet escreve o "Tratado sobre o Homem" no qual apresenta a ideia de homem médio fundamentada no pressuposto de que, se "alguém pode perguntar se existe, em um povo, um homem-tipo, que represente o seu povo pela altura e em relação a tudo o que os outros homens, do mesmo povo, podem oferecer como desvios para mais ou para menos" (QUETELET apud 
O homem médio é, portanto, o resultado da média de características físicas e morais que são frequentes na população. Essa ideia de medir as qualidades físicas e morais de uma nação e sumarizá-las em uma média produziu a ideia de normalidade, sendo o normal associado às características frequentes encontradas na sociedade ${ }^{4}$, enquanto o anormal era associado aos desvios ou às diferenças referentes àquela frequente característica populacional.

No entanto, vale ressaltar que, mais do que a introdução da ideia de normalidade, Quetelet transformou a média propriamente dita em uma quantidade real, a partir da qual as políticas do governo passam a ser orientadas, assim como são recriados esquemas de classificação, os quais julgam os indivíduos sempre em comparação com o homem médio.

\section{e) Terceiro momento: do patológico ao normal}

A ideia de homem médio propiciou o desenvolvimento da noção de normalidade, pois quem se aproximava da média da população era "normal", enquanto quem pertencia a algum desvio, tanto para mais, quanto para menos, poderia ser classificado como anormal ou até mesmo patológico. Nesse terceiro momento, utilizo o exemplo da taxa de suicídio para a reflexão sobre a noção de normalidade que, posteriormente, passa a ser expressa por índices.

No século XVIII, as doenças, as mortes e os suicídios eram vistos como comportamentos desviantes, como problemas ou, ainda, como patologias de uma sociedade. No século XIX, particularmente a partir de Quetelet, o que era considerado normal correspondia às médias da população (HACKING, 1990, p. 172). No entanto, no final do século XIX, Émile Durkheim vivenciou o seguinte dilema: se a normalidade era o resultado médio de uma característica da população, a existência de taxas médias de suicídio transformaria o suicídio em algo normal? A resposta de Durkheim é positiva. Ou seja, segundo o autor, o suicídio deveria ser considerado como um elemento social normal para a existência da sociedade.

Nesse sentido, as taxas de suicídios passaram a ser consideradas normais, pois elas vinham da sociedade e, portanto se constituíam como parte da mesma, sendo impossível eliminá-las. Porém, se o suicídio é inerente à sociedade, o que determinaria a taxa de suicídio ou ainda, a sua média?

Para Durkheim, as taxas de suicídio são influenciadas pela própria sociedade vista como uma coletividade maior do que a soma de seus indivíduos. A taxa de suicídio é um fato social, pois é geral, coercitivo e externo ao indivíduo.
4. A ideia de normalidade está associada à curva de Gauss, que possui um formato de um sino. Qual seria a probabilidade de, ao jogarmos uma moeda, tirarmos cara ou coroa? A curva de Gauss procura medir a quantidade de vezes que tiramos a cara. Ao verificar que temos maior tendência de tirarmos cara, a curva registrará um acerto nas vezes que tiramos cara e um erro para as vezes que tiramos coroa. Neste sentido surge a ideia de normalidade (acerto) e desvio (erro). 
O suicídio seria condicionado por forças externas ao indivíduo e "é necessário que elas sejam sociais" (DURKHEIM, 1983, p. 171). Como Hacking (1990, p. 177) nos afirma "Quetelet fez da média da população tão real quanto a posição de uma ilha ou de uma estrela. No tempo de Durkheim, as leis do desvio elas mesmas se tornaram parte da realidade". A taxa de suicídio seria construída a partir dos dados da população, mas quando se transforma em uma média, a taxa de suicídio ganha autonomia perante a população adquirindo poderes para classificar e construir tipos de pessoas na sociedade.

Durkheim não só contribuiu para a inserção da ideia de normalidade em fatos considerados patológicos como, ao considerar as taxas de suicídio como um fato social, contribuiu para essa nova concepção sobre o determinismo em nossa sociedade: saíamos do determinismo divino, para entrar sob o reinado do determinismo social, na forma de índices, como, por exemplo, o índice de suicídio.

Em suma, o século XIX foi marcado por avanços importantes, aqui exemplificados nesses três momentos, que ilustram as mudanças na evolução do modo de pensar sobre a sociedade e o Estado. Em um primeiro momento "descobrimos" a frequência de acontecimentos regulares inerentes a uma grande população. Em um segundo momento, a existência de constantes na população nos leva ao homem médio, o qual se transforma em uma entidade normal e real. Em um terceiro momento, as médias desviantes também são normais e reais contribuindo para a evolução da teoria de que uma entidade superior e coletiva (a própria sociedade) é que determina as regularidades de seus acontecimentos e essas regularidades estariam expressas em taxas e índices.

Essa reconstrução das transformações cognitivas pelas quais a sociedade passou demonstra a necessidade de olhar para os índices não apenas como ferramentas que apresentam a média de ocorrência de um fenômeno social, econômico ou político, mas sim como ferramentas para controlar e transformar a sociedade e a sua própria constituição deve ser estudada, abrindo espaço para uma sociologia dos índices. Como afirma Miller (2005), os índices são vistos como uma "ferramenta através da qual aqueles que debatem políticas públicas conhecem e representam a sociedade e a economia, assessoram as escolhas políticas e, cada vez mais, avaliam a performance do governo".

Da mesma maneira em que "passamos em revista" por alguns elementos da reconstituição do controle do acaso na sociedade, passaremos agora a tarefa de compreender esse mesmo fenômeno, particularmente, na esfera financeira. 
As mudanças descritas na seção anterior atingiram a esfera econômica, mais particularmente, o mercado de capitais. Um exemplo é o citado por Goede (2005 [1971]) quando faz referencia às teorias que buscam a frequência com que as crises nos mercados de ações ocorriam. Willian Stanley Jevons determinou que as crises no mercado de ações ocorriam em uma média de 10,466 anos e afirmou estar "completamente convencido de que essas crises decenais dependem das variações metereológicas do período, as quais dependem, em toda probabilidade, de variações cosmológicas das quais nós temos evidência na frequência das manchas solares, auroras e perturbações magnéticas" (JEVONS, 1879 apud GOEDE, 2005 [1971], p. 103).

Jevons buscou incorporar elementos estatísticos na economia através de representações gráficas, vistas por ele como a melhor maneira de deixar os fatos econômicos "falarem por eles mesmos." (JEVONS, 1879 apud GOEDE, 2005 [1971], p. 93) A representação dos números pelos gráficos já havia sido propagada por William Playfair, no final do século XVIII, com o intuito de "reaproximar e colocar em relação, sob os olhos, as grandezas separadas tanto pelas condições e os lugares de sua coleta como pela sua natureza" (DESROSIÈRES, 1995).

A preocupação de Jevons sobre a existência de uma regularidade nas crises do mercado de capitais influenciou Charles Dow, que buscou prever as flutuações do mercado financeiro através do cálculo da média dos preços das ações. Se, por um lado, Jevons associava as crises às mudanças climáticas, por outro, Dow explicava as flutuações dos preços por causas naturais intrínsecas ao mercado financeiro (GOEDE, 2005 [1971]). Segundo Goede (ibidem, p. 104), "a imagem dos mercados financeiros como um sistema natural e a média de preços como um termômetro se tornou cada vez mais importante".

A ideia de média, como uma entidade representativa de um todo, invadiu a esfera financeira, culminando no pioneirismo de Dow ${ }^{5}$ em criar índices para medir e prever a variação de preços no mercado de capitais.

Prever as flutuações dos preços das ações a partir de uma média calculada a partir das flutuações passadas consiste na chamada Análise Técnica ou Grafismo. Como afirma Godechot (2005 [2001], p. 218), o seu princípio geral é o de "prever o curso [das ações] a partir de seu passado".

Se, por um lado, Dow influenciaria o desenvolvimento da análise técnica, por outro, seu contemporâneo Louis Bachelier "fundou" ${ }^{6}$ a análise fundamentalista, que consiste em outra forma de previsão sobre o mercado de capitais. A análise fundamentalista de Bachelier acredita na possibilidade de estimar a amplitude de variação do mercado de capitais a partir de fatos atuais ou, ainda, em, nas próprias palavras de seu criador, "a bolsa age sobre si mesma e o
5. Charles Henry Dow foi o fundador do Walt Street Jornal e do Índice Dow Jones (GODECHOT, 2005 [2001]).

6. Bachelier foi um matemático francês que escreveu uma tese intitulada "Teoria da Especulação", no começo do século XX. Porém, sua tese foi recuperada somente nos anos 1960 (GODECHOT, 2005 [2001], p. 45). 
movimento atual é função, não somente dos movimentos anteriores, mas também de sua posição atual" (BACHELIER apud WALTER, 1996, p. 876).

Ao incorporar as ideias de distribuição normal de Gauss e probabilidade utilizadas alhures Bachelier fundou as bases das finanças modernas. A ideia de distribuição normal de Gauss é baseada no fato de que um fenômeno aleatório global seria a soma de um grande número de fenômenos aleatórios elementares de pequena amplitude, como já evidenciado no exemplo das urnas de Poisson no item 1.3. Walter (1996) explicita que, analogamente, as informações elementares chegam ao mercado ao acaso, porém as suas combinações e agregações fazem com que o mercado possua uma estrutura de distribuição determinada, abrindo as portas para uma lei da probabilidade limite da variação na bolsa.

Em outras palavras, Bachelier sugere que, o fato de que "as mudanças nos preços das ações [são] inteiramente aleatórias significa que o limite dos movimentos do preço das ações através de um período determinado pode ser calculado" (GOEDE, 2005, [1971] p. 126).

Os trabalhos de Dow e Bachelier criaram uma oposição entre aqueles que creem que a eficiência do mercado advém de informações obtidas pelas mudanças passadas e sucessivas do mercado explicitadas em um gráfico, versus aqueles que se baseavam na inteligência do operador em incorporar as informações adquiridas no momento para estimar o curso das ações.

As ideias de Bachelier influenciaram a retomada, nos anos 1970, do mercado de futuros que havia sido banido em 1934. A sua recuperação é atribuída à fórmula criada por Black e Scholes, baseada na teoria de que "o preço das opções poderiam ser calculados se já se soubesse o preço atual da ação e a volatilidade média de uma ação específica" (GOEDE, 2005 [1971], p. 128). Essa fórmula possibilitou o desenvolvimento do status científico dos mercados futuros, diminuindo o risco das operações atuais e possibilitando a criação de carteiras de investimento com pouco risco (cf. MACKENZIE, 2002; GODECHOT, 2005 [2001]).

7. Como, por exemplo, o cálculo de Value at Risk, desenvolvido por J. P. Morgan em reação ao crash de 1987. O cálculo oferecia uma medida diária de potenciais perdas (GO$E D E, 2005$, p. 138).
Devido à fórmula desenvolvida por Black e Scholes, o final do século XX presenciou o surgimento de instrumentos financeiros, cujos cálculos probabilísti$\cos ^{7}$ procuravam prever o inesperado ou, ainda, prever e calcular não apenas o desempenho, como também os riscos inerentes a uma operação. Assim, não somente os preços estavam sujeitos a uma distribuição normal, como também os riscos. Se, em um primeiro momento, o risco ocupa, no mundo financeiro, uma posição análoga à do suicídio, visto como uma patologia, em um segundo momento, a previsão do risco se torna uma parte funcional do mercado financeiro, da mesma forma que as taxas de suicídio foram vistas por Durkheim 
como uma parte funcional da sociedade.

A gestão do risco possibilitou que o cálculo sobre incertezas atingissem esferas para além da financeira, como, por exemplo, um "dilema sobre a produção de um filme" (GOEDE, 2005 [1971], p. 104).

Seja a partir da mente de um analista técnico, seja pela de um analista fundamental, a busca pelo domínio do acaso ou, ainda, pela sua previsão, inseriu-se no mercado de capitais, em particular, e no espaço financeiro, em geral. A crença nas regularidades no mercado financeiro dotou àqueles que poderiam identificá-las de poderes semelhantes aos do Estado Estatístico. Ambos baseiam-se em classificações e índices como ferramentas legitimadoras para a tomada de decisões, tornam o "improvável" ou o "pouco provável" em algo mensurável e fabricam índices pelos quais a sociedade (a qual inclui o mercado financeiro) vai ser classificada e construída.

\section{a) Os índices financeiros}

Os índices do mercado financeiro foram uma invenção de jornalistas no final do século dezenove, com o intuito de sumarizar diariamente as flutuações das ações de empresas (HAUTCEUR, 2006; GOEDE, 2005 [1971]). Segundo Hautcœur, as evidências dos dois primeiros índices publicados apareceram na Banker's Magazine, da Inglaterra, e na Customer's Afternoon Letter, dos Estados Unidos da América, antecessora do Wall Street Journal.

Como citado na seção anterior, foi Charles H. Dow quem publicou a ideia de medir diariamente o nível geral de cotação de títulos na Bolsa de Valores de Nova lorque, "calculando a cotação média de certas ações de empresas que eram consideradas representativas no ramo de ferrovias" (ZAJDENWEBER, 1991, p. 121).

Segundo Goede (2005 [1971]), além de publicar uma média aritmética das flutuações dos preços, uma das maiores inovações da publicação de Dow foi o fato de objetivar as informações financeiras, utilizando-se, para tanto, de representações numéricas. Após a crise de 1929 , os números passaram a ser divulgados sem comentários, ressaltando a capacidade dos números de "falarem por si mesmos", o que, por sua vez, atribuiu-lhes certo grau de cientificidade. Esse status científico acabaria por contribuir para a construção do mercado financeiro considerado como um espaço para pesquisas científicas, em detrimento de um espaço de jogos de azar utilizado por apostadores.

$\mathrm{Na}$ tentativa de recuperar o momento em que os índices passam a ganhar maior expressão, Hautcœur argumenta que, apesar de surgirem, em jornais 
8. Atual Standard \& Poor's, empresa privada em produção de informações financeiras.

9. Hautcœur demonstra em seu artigo que, enquanto os índices financeiros eram extremamente utilizados, nos Estados Unidos, a partir da sua publicação nos jornais da mídia financeira, no final do século XIX, na França não havia menção a eles nos jornais similares. Dentre os vários motivos que poderiam explicar essa aceitação tardia da França é a resistência de certos economistas acadêmicos (que recusavam inserir estatísticas em suas análises econômicas) e da mídia. A construção desses indicadores adveio dos economistas engenheiros que trabalhavam pela produção de estatísticas para o Estado e que viriam a desenvolver os escritórios governamentais de estatística do governo: o SGF (que publicava o único índice financeiro, na França, durante o período entreguerras) e em seguida, o Institut National de la Statistique et des Études Économiques (INSEE).

10. Fala de Luiz Ribeiro, gestor de fundos do banco HSBC. especializados em assuntos econômicos e financeiros, o crescimento do interesse por estes índices adveio da tentativa dos economistas americanos e franceses, do início do século XX, em medir a situação macroeconômica de seus respectivos países.

É interessante observar no trabalho de Hautcœur, as evidências do crescimento dos índices financeiros na França e nos Estados Unidos, a partir de diferentes esferas sociais. Enquanto, nos Estados Unidos, os índices já eram massivamente publicados pela esfera privada dos jornais financeiros e, posteriormente, pela Standard Company ${ }^{8}$, na França o espaço da academia, (através dos economistas engenheiros ${ }^{9}$ ) e do Governo foi quem contribuiu para a popularização desses indicadores.

Na tese de Hautcœur, a evolução da macroeconomia acabou por influenciar a maneira como esses índices foram construídos. A seleção de empresas para um indicador considerava aspectos macroeconômicos, como, por exemplo, a preocupação em agrupar nas carteiras, empresas representativas de todos os setores da economia. Como afirma Goede (2005 [1971]), o contexto do surgimento dos índices financeiros, nos Estados Unidos, teve uma importância particular na emergência do espaço financeiro, visto como um domínio profissional e coerentemente observável, através do qual, especificamente os índices Dow Jones se tornariam os medidores autoritários do "bem estar econômico nacional" e do mercado de capitais, em particular.

No caso do Brasil, o Índice da BOVESPA (IBOVESPA) é considerado uma medida do desempenho econômico nacional. Existe também o Índice de Sustentabilidade Empresarial (ISE), o qual procura representar e medir as práticas de responsabilidade social das empresas brasileiras listadas na bolsa de valores. Esse índice foi lançado em 2005 e constitui uma ferramenta de gestão do risco, impulsionada pela crença de que empresas que praticam a sustentabilidade têm maior rendimento financeiro, pois têm menor risco. Essa ideia fica evidenciada nas falas daqueles que atuam com esse mercado, a seguir:

(1) Essas companhias se destacam por atender critérios mínimos de saúde financeira, responsabilidade social, ambiental e governança corporativa. Teoricamente, isso significa que essas companhias apresentam menor risco aos seus acionistas. Portanto, suas ações tendem a oferecer desempenho melhor no longo prazo. (CAMBA, FARIELLO \& PAVINI, 2005)

(2) Ribeiro ${ }^{10}$ lembra que a sustentabilidade é observada pelo IFC [International Finance Corporation] na hora de conceder empréstimos para empresas, critério que vem sendo 
adotado também pelos bancos privados. Segundo ele, empresas que seguem os três pilares da sustentabilidade - respeito aos critérios sociais e ambientais, governança corporativa e baixo endividamento em relação à estrutura de capital - representam menor risco para o credor ou investidor e tendem a garantir o sucesso da empresa por um período mais longo. (PAVINI, 2005)

(3) "A Sustentabilidade confere um nível de risco menor às empresas e o investidor acaba pagando um prêmio por isso, é uma percepção que começa a se materializar", diz o superintendente de Renda Variável do Itaú, Walter Mendes. (COTIAS, 2006)

A ideia de sustentabilidade empresarial exposta pelos criadores do índice pressupõe a atuação da empresa na sociedade considerando três aspectos principais: a economia, o meio ambiente e a sociedade, que expressam a ideia de Triple Bottom Line (People, Planet and Profit - PPP) criada pela consultoria SustainAbility, em 1994, e difundido, no Brasil, pelo Instituto Ethos de Responsabilidade Social Empresarial (SARTORE, 2010).

Aos olhos do economista, o desempenho do ISE é o foco principal de suas preocupações, o qual busca compreender se um índice dessa natureza rende mais do que um índice formulado tradicionalmente, como por exemplo, o Ibovespa. Já, aos olhos do sociólogo, o ISE deve ser compreendido enquanto um objeto econômico, resultado de disputas culturais que buscam construir uma legitimidade do espaço econômico, dentro de um contexto maior de desenvolvimento das práticas sustentáveis na sociedade global.

A criação do ISE é a evidência da incorporação das ideias de sustentabilidade pelo espaço financeiro, o qual, ao criá-lo, recria a sua própria concepção de sustentabilidade, selecionando os tópicos que farão parte de sua avaliação do nível de sustentabilidade das empresas. Uma evidência dessa classificação e reclassificação de significados é a mudança de vocabulário, através da recente criação da sigla ESG (Environement, Social and Governance) [Meio Ambiente, Social e Governança] em substituição à sigla PPP criada pela consultoria SustainAbility ou, por exemplo, pelo desuso do termo Responsabilidade Social das Empresas, em detrimento da expressão Investimento Sustentável (SARTORE, 2010).

Essas transformações de semântica e de vocabulário advindas da constituição do ISE, na bolsa de valores do Estado de São Paulo, são representativas da disputa cultural e de poder para definir quem classifica o que é a sustentabilidade e como o faz para garantir que essa classificação seja predominantemente 
aceita e incorporada pela sociedade. Essa disputa determina a capacidade de regulação privada do ISE em direcionar e ditar quais devem ser as ações das empresas que querem fazer parte de sua carteira, ou, até mesmo, as ações daquelas que não estão com o capital aberto, mas que procuram se adaptar às tendências da financeirização da sociedade brasileira e o reconhecem e adotam como referencial.

\section{Considerações Finais}

Índices de Sustentabilidade: embate de diferentes formas de poder?

Nestas considerações finais, exponho o esboço da ideia de que, a partir de uma sociologia dos índices, podemos compreender os embates e as disputas de poder no âmbito privado e público (não estatal e estatal).

Segundo Miller (2005), o século XX é permeado pelos fenômenos da globalização e da descentralização que permitiram uma redefinição da relação entre as estatísticas e o Estado, ilustrada pelos índices de sustentabilidade locais, nacionais e mundiais, vistos como "tecnologias através das quais as pessoas estão produzindo novas maneiras de conhecer e ordenar o mundo nestas escalas" (MILLER, 2005, p. 405).

Pinter, Hardy e Bartelmus (2005), assim como Siche et al. (2007), situam o contexto de aparecimento e expansão dos Índices de Sustentabilidade a partir do capítulo 40 da Agenda 21, o qual propõe a criação de índices "para dar conta dos avanços feitos pelo desenvolvimento sustentável” (PINTER, HARDY \& BARTELMUS, 2005, p. 1).

Esses índices aparecem em esferas como a estatal, acadêmica ou do terceiro setor, como o Environmental Sustainability Index (ESI), criado em 2002, com o intuito de comparar os avanços ambientais das nações para as próximas décadas. Mas, também, é possível observar a sua criação na esfera financeira, como o Dow Jones Sustainability Index (DJSI), criado em 1999, com o intuito de medir a performance financeira de empresas sustentáveis, no qual o próprio ISE foi inspirado.

O ESI foi elaborado a partir da parceria entre a Universidade de Yale (Yale Center for Environmental Law and Policy), Columbia (Center for International Earth Science Information Network Columbia University), o Joint Research CentreEuropean Comission e o Fórum Econômico Mundial. Já o DJSI foi resultado da cooperação entre o STOXX Ltd., Dow Jones Indexes Co. e SAM. Ou seja, 
enquanto o primeiro é resultado da esfera acadêmica e de grupos de líderes nacionais, o segundo é resultado de grupos privados que lidam com o setor financeiro.

Considerando o fato de que o mundo das finanças teve uma ascensão no inicio do século XXI, tanto em termos econômicos, quanto culturais (GRÜN, 2004; 2005), o papel social desses índices financeiros está longe de ser menosprezado. Uma das evidências da difusão desses índices de sustentabilidade em uma escala global é o fato de que a criação do DJSI levou à criação do FTSE4Good na Inglaterra, em 2001, do Johannesburg Stock Exchanges (JSE) na África do Sul, em 2004, e do Índice de Sustentabilidade Empresarial no Brasil, em 2005. Como exposto anteriormente neste artigo, esses índices intentam expressar a ideia sobre o que o mercado financeiro considera ser relevante em termos de sustentabilidade (cf. SARTORE, 2009).

A criação desses índices coloca em evidência a necessidade de compreendermos a relação entre os atores sociais que colocam a sustentabilidade no espaço das finanças e os atores sociais promotores de outros índices de sustentabilidade, como, por exemplo, os Indicadores de Desenvolvimento Sustentável do Instituto Brasileiro de Geografia e Estatística (IBGE) ou, ainda, mais recentemente, a demanda de cientistas pela mudança do índice que mede o produto interno bruto (PIB) para que seja verde, o PIB verde (CHIARETTI, 2012). Todos esses índices sustentáveis expressam a disputa pela representação legítima da sustentabilidade, em uma linguagem universalmente aceita e reconhecida: a linguagem numérica. No entanto, a sua constituição não representa apenas uma maneira de medir uma entidade, mas sim de criar, na forma de um nominalismo dinâmico, ferramentas de poder que, ao mesmo tempo em que descrevem, criam a realidade social.

Com base no exposto, finalizo este artigo com a hipótese de que o campo composto pelos atores sociais, por detrás da criação de índices de sustentabilidade, consiste em um bom ponto de partida para evidenciar as lutas simbólicas no campo global do poder. Para além, a ideia de evaluation cultures (MACKENZIE 2010), que foca os processos culturais por detrás da construção desses valores numéricos, pode ser um bom enfoque analítico para compreender as relações de poder inscritas nesses índices. Mais especificamente, os "esforços para determinar o valor econômico das ferramentas financeiras" (MACKENZIE, 2011), que buscam representar uma realidade social, podem revelar a lógica da relação entre Estado, mercado financeiro e sociedade.

Acredito que a relevância desta revisão teórica sobre a ascensão da sociedade estatística, pautada por índices, consiste em dar suporte para o desenvolvimento de pesquisas empíricas que comprovem a hipótese delineada nesta consideração final. 
Abstract: This article consists of a theoretical study aiming to contribute to the debate on the need for a new sociological approach in Brazil which not only uses indices as analytical tools for researching, but also, thinks on how contemporary society was reoriented and reconfigured by them. I do that by theoretically drawing this new research area by using some ideas of Foucault, Hacking, Porter, Desrosières and Goede. Finally, I point out the emergence of sustainability indexes in the public sphere, as well as in the financial sphere, as central issues to the understanding of the current power configurations in the Brazilian society, which is, in turn, increasingly incorporating these tools to measure different aspects of social reality.

Keywords: Indexes, Governement, Financial Markets, Sustainability, Sociology of Science.

\section{Referências}

BOURDIEU, P. A Dominação Masculina. Rio de Janeiro: Bertrand Brasil. Tradução. Maria Helena Kühner, 1999.

CAMBA, D; FARIELLO, D \& PAVINI, A. "ISE nasce para o investidor que quer muito mais do que o lucro". Valor online 02/12/2005. [internet] Disponível em <http:// www.valoronline.com.br/valoreconomico/285/eueinvestimento/49/ISE+nasc e+para+investidor+que+quer+muito+mais+que+o+lucro,,,49,3412290.html> Acessado em 28/11/2006

CAMINHA, P. V. A Carta de Pero Vaz de Caminha, 1500. Disponível em <http:// www.culturabrasil.org/carta.htm> Acessado em 18 de janeiro de 2009.

CHIARETTI, D. "Rio+20 deveria lançar "novo PIB", sugerem cientistas". Jornal Valor Econômico 06.03.2012.

COTIAS, A. "Responsabilidade à prova". Valor Online. 23/11/2006 Disponível para assinantes em http://www.valoronline.com.br/valoreconomico/285/ eueinvestimento/49/Responsabilidade+a+prova,,,49,4018166.html

DESROSIÈRES, A. "Entre a ciência universal e as tradições nacionais. In BESSON, Jean-Louis". A ilusão das estatísticas. São Paulo: Ed. UNESP. 1995, p. 167-182.

- "Do singular ao geral: a informação estatística e a construção do Estado". Informação para uma sociedade mais justa. Organizada pelo Instituto Brasileiro de Geografia e Estatística. Rio de Janeiro, 27 a 31 de Maio de 1996.

. "The history of statistics as a genre: styles of writing and social uses". Statistical internationalism, state practices, and national traditions: progress report and prospects in the history of statistics. Montreal, Canada, 2001 (1999, 1a ed). 
DIDIER, E. "Do Statistics “Perform” the Economy?" In: Mackenzie, D. et al (orgs). Do Economists Make Markets? On the Performativity of Economics. Princeton University Press, 2007, p. 276-310.

DURKHEIM, E. O suicídio. 2a Ed. São Paulo: Abril Cultural. 1983. (Coleção Os Pensadores). Organizador José Arthur Giannotti

FOUCAULT, M Dits et Écrits. Paris: Gallimard, v.3. Direção de Daniel Defert e François Ewald (Coleção Bibliothèque des sciences humaines), 1994.

FRANÇA, V."São Paulo envelhece e jovens deixam de ser maioria no Estado”. Valoronline. 8 de junho, 2007. Disponível em <http://www.estado.com.br/editorias/2007/06/08/cid-1.93.3.20070608.10.1.xml>Acessoem24deJaneirode2009.

GODECHOT, O. Les Traders - Essai de Sociologie des marchés financiers. Paris: La Découverte, 2005 (2001, 1a ed.).

GOEDE, M. Virtue, Fortune and Faith - a Genealogy of finance. Minneapolis: Borderlines Series, 2005 (1971, 1a Ed.).

GRÜN, R. "A Evolução Recente do Espaço Financeiro no Brasil e Alguns Reflexos na Cena Política." DADOS - Revista de Ciências Sociais. Rio de Janeiro, v. 47, n. 1, 2004, p. 5-47.

. "Convergência Das Elites E Inovações Financeiras: a governança corporativa no Brasil". Revista Brasileira de Ciências Sociais, v. 20, n. 58, 2005.

HACKING, I. "Making up people". Reconstructing Individualism - autonomy, individuality and the self in western thought. Stanford University Press, 1986.

. The taming of chance. Cambridge: University Press, 1990.

HAUTCCEUR, P-C "Why and How to measure stock markets fluctuations? The early story of stock markets indices, with special reference to the French case." PSE Working Papers. Paris/França. 2006. Disponível em <http://www.pse.ens.fr/ document/wp200610.pdf> Acesso em 04 de dezembro de 2008.

IBGE. Comunicação social. 10 de setembro, 2008. Disponível em <http://www. ibge.gov.br/home/presidencia/noticias/noticia_visualiza.php?id_noticia=1226\&id_pagina=1> Acessado em 18 de Janeiro de 2009 
LYRA, P. de T. "Brasil Melhora Índices, mas segue em 70 no ranking do desenvolvimento". Valoronline 19 de dezembro, 2008. Disponível em <http:// www.valoronline.com.br/ValorOnLine/MateriaCompleta.aspx?tit=Brasil\%20 melhora\%20\%C3\%ADndices,\%20mas\%20segue\%20em\%2070\%C2\%BA\%20 no\%20ranking\%20do\%20desenvolvimento\&codmateria $=5330709 \&$ dtmater ia $=19 \% 2012 \% 202008 \&$ codcategoria $=5 \& p=61 \& t=12 p x>$ Acessado em 18 de Janeiro de 2009.

MACKENZIE, D. "Mathematizing Risk: Markets, Arbitrage and Crises". Workshop on organisational encounters with risk. 3-4 de Maio de 2002. Inglaterra. London School of Economics.

. "The credit crisis as a Problem in the Sociology of Knowledge". Working Paper, 2010 Disponível em http://www.sps.ed.ac.uk/_data/assets/ pdf_file/0019/36082/CrisisRevised.pdf Acesso em 04 de novembro de 2010.

Evaluation Cultures? On Invoking 'Culture' in the Analysis of Behaviour in Financial Markets. Working Paper, 2011. Disponível em http:// www.sps.ed.ac.uk/_data/assets/pdf_file/0007/64564/EvalCults11.pdf Acesso em 09 de novembro de 2012.

MILLER, C. A."New Civic Epistemologies of Quantification: making sense of indicators of Local and Global Sustainability". Science, Technology and Human Values. Sage Publications, v.30, n.3, 2005, p. 403-432.

PAVINI, A. "HSBC cria fundo de ações atrelado ao ISE". Valor online 29/12/2005 Disponível para assinantes em <http://www.valoronline.com.br/valoreconomico/285/eueinvestimento/49/HSBC+cria+fundo+de+acoes+atrelado+ao+I $\mathrm{SE}_{,,}, 49,3460586$. html $>$ Acessado em 28/11/2006

PINTER, L.; HARDI P. \& BARTELMUS, P. “Indicators of Sustainable Development: Proposals for a Way Forward". Expert group meeting on indicators of sustainability development. 13-15 de dezembro de 2005. New York. Disponível em <http://www.iisd.org/pdf/2005/measure_indicators_sd_way_forward.pdf> Acessado em 21 de Abril de 2009.

PORTER, T. M. The rise of statistical thinking 1820-1900. New Jersey: Princeton University Press, 1986.

SANTOS, H. D “Disciplina e Regulação: os dois pólos do poder das estatísticas". Revista Bahia Análise \& Dados Salvador v. 15, n. 01, 2005, p. 23-33.

SARTORE, M. S. "An essay on Stock Markets Sustainability Index Committees". SASE. Julho de 2009, Paris-França. 
SARTORE, M. S. Convergência de Elites: a Sustentabilidade no mercado financeiro. São Carlos, p. 208. Tese de Doutorado. Universidade Federal de São Carlos, 2010.

SICHE, R.; AGOSTINHO, F.; ORTEGA, E. \& ROMEIRO, A. "Índices versus Indicadores : precisões conceituais na discussão da sustentabilidade de países". Ambiente e Sociedade Campinas, v. 2, 2007, p.137-148, Jul/Dez.

WALTER, C. "Une histoire du concept d'efficience sur les marchés financiers". Annales HSS n.4, 1996, p. 873-905.

ZAJDENWEBER, D. "Chronique d'un randonneur centenaire: le DOW JONES". Histoire et Mesure. v.6, n.1, 1991. Disponível em <http://www.persee.fr/showPage.do?urn=hism_0982-1783_1991_num_6_1_1387> Acesso em 14 de Maio de 2008 